\title{
Review
}

\section{Antioxidant systems and oxidative stress in the testes}

\author{
R. John Aitken* and Shaun D. Roman \\ ARC Centre of Excellence in Biotechnology and Development; Discipline of Biological Sciences; University of Newcastle; Callaghan Australia
}

Key words: spermatogenesis, oxidative stress, antioxidant enzymes, reactive oxygen species, testes

\section{Introduction}

Spermatogenesis is an extremely active replicative process capable of generating approximately 1,000 sperm a second. The high rates of cell division inherent in this process imply correspondingly high rates of mitochondrial oxygen consumption by the germinal epithelium. However, the poor vascularization of the testes means that oxygen tensions in this tissue are low $^{1}$ and that competition for this vital element within the testes is extremely intense. Since both spermatogenesis ${ }^{2}$ and Leydig cell steroidogenesis ${ }^{3,4}$ are vulnerable to oxidative stress, the low oxygen tension that characterizes this tissue may be an important component of the mechanisms by which the testes protects itself from free radical-mediated damage. In addition, the testes contain an elaborate array of antioxidant enzymes and free radical scavengers to ensure that the twin spermatogenic and steroidogenic functions of this organ are not impacted by oxidative stress. These antioxidant defence systems are of major importance because peroxidative damage is currently regarded as the single most important cause of impaired testicular function underpinning the pathological consequences of a wide range of conditions from testicular torsion to diabetes and xenobiotic exposure. This chapter sets out the specific nature of these antioxidant defence systems and also reviews the factors that have been found to impair their activity, precipitating a state of oxidative stress in the testes and impairing the latter's ability to produce viable spermatozoa capable of initiating and supporting embryonic development.

\section{Antioxidant Enzymes}

Despite the low oxygen tensions that characterize the testicular micro-environment, this tissue remains vulnerable to oxidative stress due to the abundance of highly unsaturated fatty acids (particularly 20:4 and 22:6) and the presence of potential reactive oxygen species (ROS)-generating systems. ROS generation can be from the mitochondria and a variety of enzymes including the xanthine- and NADPH- oxidases, ${ }^{5,6}$ and the cytochrome P450s. ${ }^{7}$ These enzymes specialize in the professional generation of ROS or produce these

${ }^{*}$ Correspondence to: R. John Aitken; ARC Centre of Excellence in Biotechnology and Development; Discipline of Biological Sciences; University of Newcastle; Callaghan NSW 2308 Australia; Email: john.aitken@newcastle.edu.au

Previously published online as an Oxidative Medicine and Cellular Longevity E-publication: www.landesbioscience.com/journals/oximed/article/6843

Reprinted from: Molecular Mechanisms in Spermatogenesis, edited by C.Y. Cheng @ 2007 Landes Bioscience. toxic metabolites as an inadvertent consequence of their biochemical activity. In order to address this risk, the testes have developed a sophisticated array of antioxidant systems comprising both enzymatic and non-enzymatic constituents. Concerning the enzymatic constituents of this defence system, the induction of oxidative stress in the testes precipitates a response characterized by the NFKB mediated induction of mRNA species for superoxide dismutase (SOD), glutathione peroxidase (GPx) and glutathione-S-transferase (GST) activities. ${ }^{8}$ The fundamental biochemistry of these antioxidant enzymes is summarized in Figure 1 and involves the rapid conversion of superoxide anion $\left(\mathrm{O}_{2}^{-} \cdot\right)$ to hydrogen peroxide $\left(\mathrm{H}_{2} \mathrm{O}_{2}\right)$ in the presence of SOD in order to prevent the former from participating in the formation of highly pernicious hydroxyl radicals. The $\mathrm{H}_{2} \mathrm{O}_{2}$ generated in this manner is a powerful membrane permeant oxidant in its own right that has to be rapidly eliminated from the cell in order to prevent the induction of oxidative damage to lipids, proteins and DNA. The elimination of $\mathrm{H}_{2} \mathrm{O}_{2}$ is either effected by catalase or glutathione peroxidase, with the latter predominating in the case of the testes. ${ }^{9,10}$ GST on the other hand involves a large and complex family of proteins that catalyse the conjugation of reduced glutathione via the sulfhydryl group to electrophilic centres on a wide variety of substrates in preparation for excretion from the cell. This activity is critical in the detoxification of peroxidised lipids as well as the metabolism of xenobiotics.

Given the importance of SOD in this defence strategy, it is not surprising that the testes contain not only the conventional cytosolic $(\mathrm{Cu} / \mathrm{Zn})$ and mitochondrial $(\mathrm{Fe} / \mathrm{Mn})$ forms of SOD but also feature an unusual form of extracellular SOD, (SOD-Ex) which is produced by both Sertoli and germ cells, particularly the former. There is also some evidence that the germ cells may stimulate the secretion of SOD-Ex by Sertoli cells through the actions of cytokines such as interleukin-1 $\alpha .{ }^{11}$ The importance of the cytosolic form of SOD (SOD1) was recently emphasised in studies of SOD1-knockout mice subjected to testicular heat stress. This treatment induced significantly enhanced levels of DNA strand breakage and cytochrome C leakage from the mitochondria of germ cells in these animals compared with the wild-type controls. ${ }^{12}$ Similarly, the importance of the mitochondrial form of SOD (SOD2) in controlling $\mathrm{O}_{2}^{-\cdot}$ leakage from testicular mitochondria has been emphasised by the finding that the mRNA for this enzyme is markedly higher in the testes than the liver, unlike GPx and catalase. ${ }^{13}$ Moreover, SOD-2 mRNA levels are developmentally and translationally regulated with maximal levels of expression in early post-meiotic germ cells. ${ }^{13}$ 
Figure 1. Major pathways of reactive oxygen species generation and metabolism. Superoxide can be generated by specialized enzymes, such as the xanthine or NADPH oxidases, or as a by-product of cellular metabolism, particularly the mitochondrial electron transport chain. Superoxide dismutase then converts the superoxide to hydrogen peroxide which has to be rapidly removed from the system. This is generally achieved by catalase or peroxidases, such as the glutathione peroxidases which use reduced glutathione (GSH) as the electron donor.

Although catalase is of limited importance in the testes, there are several isoforms of GPx in this tissue that use glutathione (GSH) as a source of electrons to reduce $\mathrm{H}_{2} \mathrm{O}_{2}$ to water. They are concentrated in the mitochondria, nucleus and acrosomal domain of differentiating spermatozoa. ${ }^{14}$ The phospholipid hydroperoxide GPx (PHGPx) is one of the most important GPx isoforms in a testicular context and is highly expressed in both spermatogenic and Leydig cells. ${ }^{15}$ Since most forms of GPx are selenium dependent it is possible to gauge the importance of these enzymes in the support of testicular function by examining the impact of selenium deficiency on male reproduction. Animals fed on a selenium deficient diet exhibit a significant reduction of testicular GPx activity and an accompanying loss of germ cells from the germinal epithelium of the testes. ${ }^{16}$ Moreover, selenium administration prior to the creation of oxidative stress in the testes using the torsion/detorsion model (see later) to create ischemia-reperfusion injury, has been found to suppress lipid peroxidation and improve the histopathological profile. ${ }^{17}$

\section{Small Molecular Mass Antioxidants}

In addition to the major ROS processing enzymes, the testes rely heavily on small molecular weight antioxidant factors for protection against oxidative damage. These factors include ions and a wide variety of free radical scavengers, the nature of which are reviewed below.

Zinc. Zinc is an acknowledged antioxidant factor that as well as being a core constituent of free radical scavenging enzymes such as SOD and a recognized protector of sulfhydryl groups, is also thought to impair lipid peroxidation by displacing transition metals such as iron and copper from catalytic sites. ${ }^{18}$ In keeping with such a central antioxidant role, this element has a profound effect on the level of oxidative stress experienced by the testes. Thus rats fed a zinc deficient diet experience a decrease in testicular antioxidant potential and a concomitant increase of lipid peroxidation in this tissue. ${ }^{19}$ Conversely, zinc administration will counteract the oxidative stress created in the testes by exposure to lead..$^{20-21}$ as well as the peroxidative damage induced by ischemia-reperfusion as a consequence testicular torsion-detorsion. ${ }^{22}$ Zinc administration has also been shown to attenuate the testicular oxidative DNA damage induced by cadmium as well as the decline in sperm production and testosterone secretion induced by this heavy metal. ${ }^{23}$

Vitamins C and E. It has been recognized since the 1940 s that vitamin $\mathrm{E}$ ( $\alpha$-tocopherol) is a powerful lipophilic antioxidant that is absolutely vital for the maintenance of mammalian spermatogenesis. ${ }^{24}$ It is present in particularly high amounts in Sertoli cells and pachytene spermatocytes and to a lesser extent round spermatids. ${ }^{25}$ Vitamin C (ascorbic acid) also contributes to the support of spermatogenesis at least in part through its capacity to reduce $\alpha$-tocopherol and maintain this antioxidant in an active state. Vitamin $\mathrm{C}$ is itself maintained in a reduced state by a GSH-dependent dehydroascorbate reductase, which is abundant in the testes. ${ }^{26}$ Deficiencies of vitamins $\mathrm{C}$ or $\mathrm{E}$ leads to a state of oxidative stress in the testes that disrupts both spermatogenesis and the production of testosterone. ${ }^{24}$ Conversely, ascorbate administration to normal animals stimulates both sperm production and testosterone secretion. ${ }^{27}$ This vitamin also counteracts the testicular oxidative stress induced by exposure to pro-oxidants such as arsenic, PCBs (Arochlor 1254), cadmium, endosulfan and alcohol. ${ }^{28-32}$ Furthermore, endogenous ascorbate levels decrease dramatically when oxidative stress is induced in the testes by, for example, chronic exposure to lead, chromium, cadmium or aflatoxin. ${ }^{33-25}$ Vitamin $\mathrm{E}$ has also been shown to suppress lipid peroxidation in testicular microsomes and mitochondria 36,37 and to reverse the detrimental effects of oxidative stress on testicular function mediated by exposure to such factors as ozone, iron overload, intensive exercise or exposure to aflatoxin, $\mathrm{PCB}$, cyclophosphamide and formaldehyde. ${ }^{28,32,33,38-42}$ Furthermore testicular vitamin $\mathrm{E}$ levels have also been shown to fall significantly when oxidative stress is induced by exposure to pro-oxidant stimuli such as chromium. ${ }^{34}$ 
Melatonin and cytochrome $\mathrm{C}$. The pineal hormone melatonin $(\mathrm{N}$ -acetyl, 5-methoxytryptamine) also plays a major role in protecting the testes from oxidative stress, given the significant stimulatory effect of pinealectomy on the oxidative damage recorded in the testes as a consequence of induced hyperthyroidism. ${ }^{43}$ Melatonin has two major attributes that set it apart from most other antioxidants. Firstly, it undergoes a two electron oxidation when acting as antioxidant, rather than the one electron oxidation favoured by many free radical scavengers. As a result, this compound cannot redox cycle and inadvertently generate free radicals. Secondly, melatonin is readily soluble in both lipid and aqueous environments and can readily cross the blood-testes barrier to protect the germinal epithelium. Melatonin levels in seminal plasma are depressed in infertile patients exhibiting poor motility, leukocytospermia, varicocele and non-obstructive azoospermia, all of which are conditions associated with oxidative stress in the male tract. ${ }^{44}$ Moreover, the intraperitoneal injection of melatonin has been shown to alleviate oxidative stress in the testes following the experimental induction of a left sided varicocele. ${ }^{45}$

Another small molecular mass free radical scavenger that has recently been shown to play a major role in reducing $\mathrm{H}_{2} \mathrm{O}_{2}$ is a testes-specific form of cytochrome $\mathrm{C}$. This cytochrome $\mathrm{C}$ isoform is also a powerful activator of apoptosis, providing additional protection to the testes by virtue of its ability to facilitate the depletion of damaged germ cells. ${ }^{46}$

\section{Disruption of the Antioxidant Status of the Testes}

Notwithstanding the antioxidant protection afforded to the testes in order to support its dual functions of steroidogenesis and sperm production, a wide variety of endogenous and exogenous factors are known to perturb these defences and generate a state of oxidative stress. In the following section, some of these factors are reviewed.

Cryptorchidism. The elevated temperatures associated with experimental cryptorchidism are associated with oxidative stress in the testes and a reduction in SOD and catalase activities. ${ }^{47}$ Consistent with these findings, direct exposure of spermatogenic cells to elevated temperatures was found to induce high rates of apoptosis via mechanisms that were associated with elevated levels of $\mathrm{H}_{2} \mathrm{O}_{2}$ generation and could be ameliorated by the addition of catalase. ${ }^{48}$ Moreover the consequence of heat stress on spermatogenic cells was exacerbated in SOD1-knock out mice via mechanisms that could be reversed by the addition of Tiron, a superoxide anion radical scavenger. ${ }^{49}$ The clinical significance of this finding can be seen in the high levels of DNA damage and ROS generation seen in the spermatozoa of patients with a history of cryptorchidism. ${ }^{50}$

Testicular torsion. Testicular torsion is a relatively common, painful condition that must be treated rapidly if the testes are not to suffer permanent damage. Prolonged torsion leads to testicular ischaemia and high levels of oxidative stress in the ipsilateral testes associated with $\mathrm{NO}$ and $\mathrm{H}_{2} \mathrm{O}_{2}$ production, increased lipid peroxide formation, isoprostane accumulation, antioxidant enzyme depletion and increased rates of mitochondria-mediated apoptosis in the germ line. ${ }^{51-53}$ Even short periods of ischaemia, for 3 hours or less, can lead to a high levels of oxidative stress in the testes, depletion of testicular glutathione levels and the consequent disruption of spermatogenesis. Significantly, the level of peroxidative damage observed in testicular tissue increases following detorsion, indicating the induction of reperfusion injury. ${ }^{54}$ The biochemical basis for reperfusion injury is thought to involve a key metabolic enzyme, xanthine dehydrogenase, which becomes converted to a xanthine oxidase during ischaemia, due to oxidation of essential -SH groups and/or a limited proteolytic clip. As soon as the tissue is reperfused with blood, the xanthine oxidase is suddenly presented with oxidizable substrate in the form of xanthine/hypoxanthine and starts to generate copious amounts of ROS. The latter then induce high levels of peroxidative damage via mechanisms that are enhanced by the local release of transition metals. Although this scheme of events was developed to explain the tissue injury associated with conditions such as myocardial infarction, it also applies to the testicular injury associated with torsion-detorsion. The general notion that the testicular damage precipitated by temporary ischaemia is associated with oxidative stress is supported by the sudden induction of lipid peroxidation and the concomitant suppression of endogenous antioxidant activities including SOD, catalase and glutathione peroxidase. ${ }^{17,55-57}$ In addition, the tissue injury induced by testicular torsion/detorsion can be dramatically alleviated by pretreatment with exogenous antioxidants such as selenium, resveratrol, L-carnitine, caffeic acid phenethyl ester and garlic extract. ${ }^{17,57-60}$ Finally the enzyme purportedly associated with reperfusion injury, xanthine oxidase, can be inhibited by allopurinol and the latter is known to reduce the testicular damage associated with testicular torsion. ${ }^{56}$ Notwithstanding the importance of xanthine oxidase-mediated oxidative stress it should also be noted that neutrophil infiltration into the testes following torsion may represent yet another source of uncontrolled free radical generation responsible for mediating the pathophysiological consequences of temporary testicular ischaemia. ${ }^{61}$

One of the major issues associated with the clinical management of unilateral testicular torsion is whether the ipsilateral testis should be removed in order to preserve the contralateral testis. In animal models prolonged testicular torsion results in excessive ROS generation, depletion of antioxidant enzymes and the appearance of oxidative damage in the contralateral testes. ${ }^{62-64}$ In light of these data, surgical removal of the ipsilateral testes would seem warranted if the period of ischaemia has been extensive.

Varicocele. The impaired venous drainage to the testes seen with varicocele is also associated with the disruption of spermatogenesis via mechanisms involving the induction of oxidative stress. In clinical studies, the presence of a varicocele has been shown to correlate with excess ROS generation by the spermatozoa, high rates of DNA damage in these cells and depleted antioxidant levels in the seminal plasma. ${ }^{65-67}$ In a recent study, surgical correction of left sided varicocele was shown to significantly improve sperm concentration, total count, morphology and motility in concert with significant improvements in the antioxidant status of the spermatozoa and seminal plasma. ${ }^{68}$ This reduction in oxidative stress secondary to varicocele excision was accompanied by a reduction in both protein carbonyl expression and DNA damage in the spermatozoa. ${ }^{68}$ Independent studies have also shown that the testicular expression of 4-hydroxy-2-nonenal modified proteins (another marker of oxidative stress) is significantly higher in patients that responded positively to varicocelectomy, suggesting that surgical treatments are capable of reducing oxidative stress in the testes. ${ }^{69}$ Immunocytochemical analyses of 8-hydroxy-2'-deoxyguanosine expression in the testes of varicocele patients also revealed particularly high levels of oxidative DNA damage in the spermatogonia and spermatocytes that 
correlated well with the severity of the varicosity. ${ }^{70}$ The general concept that testicular pathologies associated with varicocele are linked with the induction of oxidative stress has been confirmed in animal models. Thus, creation of experimental bilateral varicocele in rats is associated with increases in lipid peroxidation and NO generation and a corresponding decrease in testicular antioxidant status. ${ }^{71}$ Moreover, the pathological consequences of experimental varicocele induction can be significantly reversed by the concomitant administration of an antioxidant, melatonin. ${ }^{45}$

The site of free radical generation in varicocele patients is still open to conjecture. On the one hand, enhanced free radical generation by the spermatozoa and/or precursor germ cells has been repeatedly suggested, ${ }^{65,72,73}$ on the other, there is evidence to suggest that excess free radical generation may involve the spermatic vein itself. ${ }^{74}$ The excess generation of free radicals by the spermatozoa may be an indirect consequence of impaired spermatogenesis/epididymal function resulting in the retention of excess residual cytoplasm. The presence of excess cytoplasm has been positively correlated with the generation of ROS by human spermatozoa, via mechanisms involving the facilitated supply NADPH to oxidases in the sperm plasma membrane. ${ }^{75}$ These enzymes, including NOX5 and DUOX, both of which have been identified in human spermatozoa, ${ }^{5,76}$ are normally deprived of sufficient NADPH to drive free radical generation; what hexose monophosphate shunt activity there is, being largely devoted to the maintenance of glutathione reductase activity. ${ }^{77}$ However, when excess residual cytoplasm is present the limited substrate availability is no longer an issue and free radical generation can be initiated. The relevance of this model to the oxidative stress detected in cases of varicocele is clearly suggested by the effects of varicocelectomy. Thus, not only do the spermatozoa produced by such patients exhibit high levels of ROS in association with cytoplasmic retention but also surgical correction of this condition both prevents cytoplasmic retention and suppresses ROS generation. ${ }^{73,78,79}$ A causative association between these events therefore seems likely.

Hyperthyroidism. The induction of hyperthyroidism in rats is associated with oxidative stress in the testes as reflected by increased lipid peroxidation, elevated GSH levels and induction of antioxidant enzymes. The oxidative stress appears to be associated with a thyroxine dependent increase in mitochondrial activity and concomitant leakage of electrons from the mitochondrial electron transport chain. ${ }^{80,81}$ The oxidative stress precipitated by hyperthyroidism can be exacerbated by pinealectomy removing melatonin, an important testicular antioxidant, from the redox equation. ${ }^{43}$ These data resonate with clinical studies indicating that hyperthyroidism is associated with poor semen quality, particularly impaired motility, that normalize when the patients' thyroid dysfunction is corrected and euthyroidism established. ${ }^{82}$ It should also be noted that hypothyroidism can induce oxidative stress in the testes as reflected by enhanced levels of $\mathrm{H}_{2} \mathrm{O}_{2}$ production and increased carbonyl generation. ${ }^{83}$ Clearly, normal testicular function is highly dependent on a functional thyroid system.

Diabetes. Experimental induction of diabetes in animal models has been shown to impair testicular function and decrease male fertility. Thus, diabetogens such as streptozotocin, enhance ROS generation and induce both lipid peroxidation and protein carbonyl expression in the testes. Moreover the oxidative stress associated with the diabetic condition is associated with DNA damage in the male germ line and high rates of embryonic loss in mated females (dominant lethal effect). These effects could be attenuated by the administration of antioxidants such as ascorbic acid, melatonin, taurine or an herbal mixture containing extracts from Musa paradisiaca, Tamarindus indica, Eugenia jambolana and Coccinia indica. ${ }^{84-86}$ In light of recent data showing an increased level of DNA damage in the spermatozoa of diabetic patients compared with non-diabetic controls, ${ }^{87}$ causative links between diabetes, oxidative stress in the male germ line and DNA damage appears both likely and clinically, extremely important.

Infection. Another factor that may cause oxidative stress in the testes is infection. Experimental models of infection, involving the intraperitoneal injection of bacterial lipopolysaccharide (LPS), induced lipid peroxidation in the testes and rapidly depleted this tissue of antioxidant enzyme activity in the form of SOD, catalase and the glutathione peroxidase-reductase couple. This oxidative stress was associated with the transient generation of pro-inflammatory mediators such as interleukin $1 \beta$, inducible nitric oxide synthase and cyclo-oxygenase- $2 .{ }^{88}$ The same experimental infection model has also been used to demonstrate the particular sensitivity of Leydig cell steroidogenesis to oxidative stress induced by bacterial LPS. In these studies, the oxidative stress induced by LPS stimulated lipid peroxidation in Leydig cell membranes as well as significant reductions in steroidogenic acute regulatory protein (StAR) and $3 \beta$-hydroxysteroid dehydrogenase isomerase ( $3 \beta$-HSD) activity. Moreover, these effects were associated with the disruption of Leydig cell mitochondrial function and, specifically, the inhibition of StAR-mediated cholesterol transfer activity. ${ }^{89}$

Physical exertion. Physical exercise has been shown to up-regulate antioxidant activities in the testes of aging rats and may represent a practical way in which the detrimental effects of age on testicular function can be ameliorated. ${ }^{90}$ A similar case could be argued for the ability of moderate exercise to ameliorate the degree of oxidative damage inflicted on the testes by chronic ethanol ingestion. ${ }^{91}$ However, excess exercise can have the opposite effect, causing oxidative stress in the testes and generating high levels of lipid peroxidation in association with significant declines in the activities of key antioxidant enzymes including SOD, catalase, GST and GPx. ${ }^{92}$ Such stress has a significant inhibitory effect on the both steroidogenesis and germ cell differentiation within the testes. The fact that these effects can be reversed by the administration of an antioxidant, $\alpha$-tocopherol succinate, confirms the importance of oxidative stress in the aetiology of such exercise-dependent testicular dysfunction. ${ }^{40}$

Reproductive hormone imbalance. The immediate endocrine environment of the testes has a major impact on the antioxidant status of this organ. Treatments including exposure to cyclophosphamide or dimethane sulfonate that diminish the intratesticular concentration of testosterone, inhibit the testicular expression of antioxidant enzymes such as GPx, SOD and catalase. ${ }^{93,94}$ Furthermore, these suppressive effects on antioxidant expression, as well as the disruption of spermatogenesis, can be reversed by the administration of exogenous gonadotrophin to artificially elevate intratesticular testosterone levels. ${ }^{94,95}$ Suppression of intratesticular testosterone with exogenous steroids, including both androgens and estrogens, similarly results in the suppression of antioxidant enzyme expression, a concomitant increase in peroxidative damage, the disruption of spermatogenesis and an increase in germ cell apoptosis. ${ }^{95-97}$ 
Intriguingly, the suppression of antioxidant activity in response to exogenous steroid treatment largely affects the Leydig cells that contain most of the catalase and GPx activities. Testicular SOD activities that are largely confined to the seminiferous tubules did not change dramatically under these circumstances. ${ }^{95}$ It is therefore possible that the site of free radical generation in response to gonadotrophin withdrawal involves electron leakage from the inhibited steroidogenic pathway of the Leydig cells. These free radicals then attack the germ cells within the seminiferous tubules leading to extensive apoptosis and the disruption of spermatogenesis. The fact that aminoglutethimide, an inhibitor of the P450 cholesterol side-chain cleavage, induces extensive lipid peroxidation in the testis supports this contention. ${ }^{95}$ Interestingly, over-stimulation of the Leydig cells by chronic exposure to hCG (100 IU/day for 30 days in rats) also stimulates high levels of ROS production from these cells, that in turn stimulate lipid peroxidation, reduction in antioxidant enzyme activities, germ cell apoptosis and the consequential disruption of spermatogenesis. ${ }^{98}$ Thus, as we saw with the involvement of the thyroid gland in the control of testicular function, a stable redox environment depends on an appropriately balanced gonadotrophic support, either hyper- or hypo- gonadotrophism will induce a state of oxidative stress in the testis.

Retinoids. While fluctuations in Leydig cell steroidogenesis may be one source of free radical generation in the testes, another is the Sertoli cell population. The latter has been shown to generate ROS following stimulation with all trans-retinoic acid (RA), a vital cofactor for spermatogenesis. Exposure of rat Sertoli cells to RA led to activation of ROS generation, lipid peroxidation and, ultimately, a loss of cell viability. ${ }^{99}$ There is also some evidence to suggest that retinol might stimulate ROS generation in rat Sertoli cells 99,100 and that this effect is accompanied by an upregulation of testicular antioxidant enzymes including SOD, GPx and catalase. ${ }^{101}$ There may be nothing particularly specific about this effect since retinoids have been shown to stimulate ROS generation in a variety of other cellular systems. ${ }^{102}$ Nevertheless, the free radical generation triggered by retinoids in the testes may explain the testicular degeneration induced by hypervitaminosis $\mathrm{A}$ in the rat ${ }^{103}$ and the association between excess beta carotene intake and infertility in human males. ${ }^{104}$

Impact of xenobiotics. A wide variety of different xenobiotics have also been shown to induce oxidative stress in the testes in concert with the suppression of antioxidant mechanisms. A summary of these testicular toxicants is provided in Table 1. Heavy paternal smoking, for example, is known to generate oxidative DNA damage in the male germ line in association with a $32 \%$ reduction in the $\alpha$-tocopherol content of the seminal plasma. ${ }^{105}$ The role of oxidative stress in the genesis of this DNA damage is supported by the observation that in individuals subjected to an ascorbate depleted diet, the seminal plasma ascorbate levels decreased by a half, while DNA damage levels in the spermatozoa increased by $91 \%$. Repletion of the ascorbate levels in the diet had the reverse effect and decreased DNA damage by 36\%. ${ }^{106}$ Experimental exposure of rats to cigarette smoke also induces lipid peroxidation in the testes in association with disturbances in testicular antioxidant enzyme activity. ${ }^{2}$ The testicular damage induced by cigarette smoke exposure in rats is certainly oxidative in nature because it can be reversed by concomitant exposure to an antioxidant (caffeic acid phenethyl ester). ${ }^{107}$
In addition to smoking, excessive alcohol consumption also has a negative effect of testicular function through the induction of oxidative stress and the concomitant disruption of testicular antioxidant status. ${ }^{108,109}$ Furthermore, the ability of antioxidants such as vitamin $\mathrm{C}$ or lecithin to ameliorate this pathology, confirms the importance of oxidative stress in this context. ${ }^{110-111}$ In addition to inducing low sperm counts and poor sperm motility, it also appears that the oxidative stress created in the Leydig cells as a consequence of chronic alcohol exposure diminishes the steroidogenic capacity of the testes, lowering circulating testosterone levels. ${ }^{112}$

Table 1 also highlights a number of metals that are known to induce oxidative stress in the testes and compromise male infertility. Chromium, for example, is a testicular toxicant that stimulates lipid peroxidation and suppresses antioxidant enzyme activities as well as ascorbate levels in the testes. ${ }^{113}$ Additional studies in monkeys have also shown that chromium administration decreases not only inhibit the classical array of antioxidant enzymes in the testes but also diminishes the testicular content of GSH as well as vitamins $\mathrm{A}, \mathrm{E}$ and $\mathrm{C}$, while $\mathrm{H}_{2} \mathrm{O}_{2}$ production and hydroxyl radical formation are increased. ${ }^{34}$ Additional transition metals such as iron also induce lipid peroxidation, protein carbonyl expression and lipid soluble antioxidant depletion in testicular tissue with the consequent disruption of spermatogenesis. ${ }^{114,115}$ Significantly, iron intoxication of male mice also induces a dominant lethal effect characterized by high levels of embryonic loss in females mated to iron-exposed males. In this situation, the oxidative stress induced in the testes by acute iron overload must have so damaged the DNA in the spermatozoa that the resulting embryos were non-viable.

Heavy metals such as lead, cadmium and uranium have a similar effect on the testes disrupting spermatogenesis via mechanisms that involved the induction of lipid peroxidation, depletion of ROS scavengers and disruption of testicular antioxidant enzyme activity. $35,116-118$ Arsenic has also been shown to induce peroxidative damage in the testes elevating protein carbonyl expression and decreasing tissue GSH content and inhibiting $3 \beta$ - and $17 \beta$-hydroxysteroid dehydrogenase activities. The importance of oxidative stress in the testicular toxicity associated with arsenic was emphasised by the ability of ascorbate to reverse these changes. ${ }^{119}$ Similarly, vanadate is a testicular toxicant that induces lipid peroxidation in the testes along with significant suppression of testicular SOD and catalase and the disruption of $3 \beta$ - and $17 \beta$-hydroxysteroid dehydrogenase activities. ${ }^{120}$

In addition to the above, Table 1 lists a wide variety of different industrial and environmental toxicants that are all capable of compromising male fertility by inducing a state of oxidative stress in the testes. These compounds include phthalate esters, ${ }^{121,122}$ sulfur dioxide, ${ }^{123}$ sodium fluoride, ${ }^{124}$ a range of environmental estrogens (e.g., PCBs, ${ }^{2,39,125-127}$ methoxychlor, ${ }^{128,129}$ bisphenol $\mathrm{A}^{130,131}$ nonylphenol ${ }^{132}$ ), chemotherapeutic agents (e.g., adriamycin, 135 cisplatin $^{136,137}$ cyclophosphamide ${ }^{138-140}$ ) hexachlorocyclohexane, ${ }^{141-142}$ 2,4,6-trinitrotoluene, ${ }^{143}$ aflatoxin, ${ }^{144}$ lindane, ${ }^{145}$ quinalphos ${ }^{146}$ endosulfan, ${ }^{147}$ diethyl maleate, ${ }^{148}$ monensin, ${ }^{149}$ formaldehyde, ${ }^{150}$ alloxan, ${ }^{151,152}$ streptozotocin, ${ }^{86}$ acrylamide ${ }^{153}$ and ozone. ${ }^{154}$ In addition to this list of xenobiotic chemicals that can induce oxidative stress in the testes, physical factors such as static magnetic fields ${ }^{155}$ and electromagnetic radiation in its various forms from heat ${ }^{12,156}$ to $\mathrm{X}$-ray ${ }^{157}$ irradiation, can also trigger a state of oxidative stress in 


\begin{tabular}{|c|c|c|c|}
\hline \multirow{2}{*}{$\begin{array}{ll}\text { Table } 1 \text { Lis } \\
\text { in }\end{array}$} & \multicolumn{3}{|c|}{$\begin{array}{l}\text { List of compounds capable of inducing oxidative stress } \\
\text { in the testes }\end{array}$} \\
\hline & Ref. & Compound & Ref. \\
\hline Smoking & $2,105-107$ & Nonylphenol & $132-134$ \\
\hline Alcohol & $108-111$ & Adriamycin & 135 \\
\hline Chromic acid & 34,113 & Cisplatin & $136-137$ \\
\hline Iron & 114,115 & Cyclophosphamide & $138-140$ \\
\hline Lead & 35 & Hexachlorocyclohexane & $141-142$ \\
\hline Cadmium & 116 & Trinitrotolvene & 143 \\
\hline Uranium & 118 & Aflatoxin & 144 \\
\hline Arsenic & 119 & Lindane & 145 \\
\hline Vanadate & 120 & Quinalphos & 146 \\
\hline Phthalate esters & 121,122 & Endosulfan & 147 \\
\hline Sulfur dioxide & 123 & Diethyl maleate & 148 \\
\hline Sodium fluoride & 124 & Monensin & 149 \\
\hline $\mathrm{PCB} / \mathrm{PCN}$ & $2,39,125-127$ & Formaldehyde & 150 \\
\hline Methoxychlor & 128,129 & Alloxan & 151,152 \\
\hline \multirow[t]{3}{*}{ Bisphenol A } & $1,130,131$ & Streptozotocin & 86 \\
\hline & & Acrylamide & 153 \\
\hline & & Ozone & 154 \\
\hline
\end{tabular}

MDA, malondialdehyde; $\mathrm{XO}$, xanthine oxidase; GPx, glutathione peroxidase; MPO, myeloperoxidase; iNOS, inducible nitric oxide synthase.

testicular tissue. Given the variety and prevalence of chemical and physical factors that can generate oxidative stress in the male gonad, there is an urgent need to identify antioxidants that can supplement the tissue's own antioxidant strategies to rescue the testes from the consequences of ROS attack.

\section{Antioxidant Therapy}

In order to determine the relative potential of different antioxidants to address oxidative stress in the testes, the testicular torsion-detorsion model has been repeatedly used. Typically this model involves the application of antioxidant therapy prior to the creation of a brief period of oxidative stress and subsequent comparison of various testicular attributes (lipid peroxidation, histopathology, DNA damage or antioxidant enzyme status) with sham operated controls (Table 2). Such analyses have recorded significant protection against oxidative stress for factors as garlic extract, ${ }^{57}$ caffeic acid phenethyl ester (CAPE), ${ }^{60} \mathrm{~N}$-acetyl cysteine, ${ }^{158}$ pentoxifylline, ${ }^{159}$ erdostein, ${ }^{160}$ resveratrol, ${ }^{58}$ dexpathenol, ${ }^{161}$ L-carnitine ${ }^{59}$ and propofol anaesthetic. ${ }^{162}$

A variety of antioxidants have also been assessed for their ability to counteract oxidative stress in the testes created by alternative mechanisms. For example: (1) CAPE has been shown to protect the testes from the oxidative stress created by exposure to dizocilpine (MK-801), a drug that is commonly used to induce schizophrenia, ${ }^{163}$ and cigarette smoke ${ }^{107}$ (2) lycopene, the red plant antioxidant that is a major constituent of tomatoes, is capable of reversing the oxidative damage induced in rat testes following exposure to cyclosporin $A^{164}$ or cisplatin ${ }^{137}$ (3) extracts from the herb Lycium barbarum, effectively protect the testes from the oxidative damage induced by heat stress and significantly suppress the oxidative DNA damage induced in mouse testicular cells by $\mathrm{H}_{2} \mathrm{O}_{2}{ }^{165}$ (4) MTEC (an aqueous-methanol extract of Musa paradisiaca, Tamarindus indica, Eugenia jambolana and Coccinia indica) protects against the oxidative testicular damage resulting from induced diabetes ${ }^{84}$ (5) lecithin administration protects the testes from the oxidative stress induced by chronic ethanol exposure ${ }^{11}(6)$ lipoic acid has been shown to inhibit the oxidative damage resulting from exposure to cyclophosphamide, ${ }^{140}$ adriamycin ${ }^{135}$ and X-irradiation ${ }^{157}$ (7) complex feruloyl oligosaccharides released from wheat bran have also been shown to protect the testes from the oxidative stress associated with alloxan-induced diabetes in rats ${ }^{152}$ and (8) $\beta$-carotene ameliorates cadmium induced oxidative stress in the testes, suppressing lipid peroxidation and restoring SOD, GST and GSH to normal physiological levels. ${ }^{166}$

One of the most effective antioxidants for the protection of testicular function is melatonin. This evolutionarily conserved compound has been shown to reduce oxidative stress in the testes induced by ethanol, ${ }^{167}$ indomethacin, ${ }^{168} \mathrm{X}$-irradiation, ${ }^{169}$ streptozotocin-induced diabetes, ${ }^{86}$ and cisplatin. ${ }^{136}$ In vitro studies have also shown that melatonin and its immediate precursor $\mathrm{N}$-acetyl-serotonin could inhibit ascorbate-Fe (II) induced lipid peroxidation in rat testicular microsomes and mitochondria. ${ }^{170,171}$

The administration of antioxidants such as resveratrol, ascorbate or cocoa rich in flavanols to normal animals, not suffering from induced oxidative stress, also appears to improve testicular function, suggesting that oxidative stress is a consistent feature of testicular physiology. ${ }^{172,173}$ In light of such results, antioxidants have frequently been administered to infertile men in the hope of improving the quality of the semen profile. Very few properly controlled double blind crossover trials have been conducted in this context. However where these conditions have been met, the results have been extremely promising. ${ }^{174,175}$

\section{Conclusions}

Oxidative stress is a major factor in the aetiology of male infertility. At the level of the isolated spermatozoon, ROS attack can induce lipid peroxidation and DNA fragmentation disrupting both the motility of these cells and their ability to support normal embryonic development. ${ }^{176-182}$ At the level of the testes, oxidative stress is capable of disrupting the steroidogenic capacity of Leydig cells ${ }^{183}$ as well as the capacity of the germinal epithelium to differentiate normal spermatozoa. ${ }^{184} \mathrm{~A}$ large number of independent clinical studies have demonstrated a correlative relationship between male infertility and evidence of oxidative stress in the ejaculate. ${ }^{180,185}$ Moreover the literature reviewed in this chapter reveals an abundance of experimental data in animal models demonstrating a causal relationship between the induction of oxidative stress in the testes and the impairment of male reproductive function. However these two lines of evidence have not yet come together. Although oxidative stress is clearly a dominant feature in the aetiology of male infertility, the underlying causative mechanisms remain unresolved. The plethora of physical, chemical, and pathological factors that can apparently contribute to the induction of oxidative stress in the testes is impressive and 


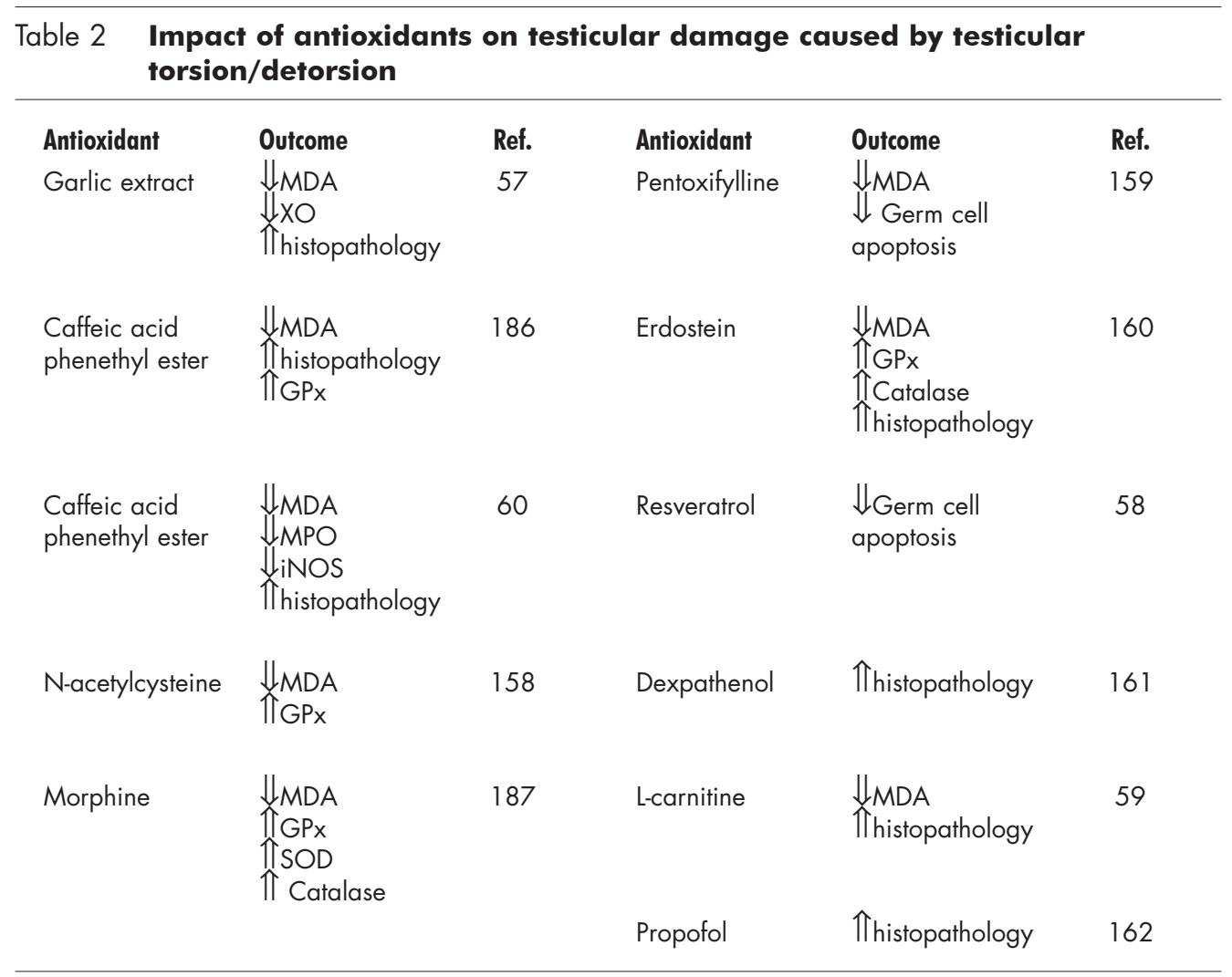

MDA, malondialdehyde; $X 0$, xanthine oxidase; GPx, glutathione peroxidase; MPO, myeloperoxidase; iNOS, inducible nitric oxide synthase.

suggests that the clinical picture will be extremely complex, with each individual being subject to a unique range of causative factors as a result of differences in occupational and environmental exposures, the presence of other pathological factors such as infection or diabetes, and genetic factors that could influence everything from the way in which specific xenobiotics are metabolised to the endocrine environment in which the testes have to function.

That there are so many factors capable of inducing oxidative stress in the testes strongly suggests that this is a vulnerable tissue that is both highly dependent on oxygen to drive spermatogenesis and yet highly susceptible to the toxic effects of reactive oxygen metabolites; in this context, the testis is very like the brain. While the testes clearly do possess highly specialized antioxidant defence enzymes such as extracellular SOD, PHGPx etc, there are clear benefits to be gained by treating susceptible individuals with exogenous antioxidants. Despite the evident clinical market for an antioxidant preparation specifically designed to support male reproductive health, it is remarkable how little effort has gone into the development of such a preparation and how poor most of the clinical trials in this area have been. In animal models an impressive range of antioxidant preparations has been examined and compounds identified that are clearly capable of crossing the blood testes barrier and protecting the germinal epithelium and Leydig cells from oxidative stress. The future imperatives for this area are to go beyond the superficial phenomenology that characterizes most of the clinical research in this area in an attempt to (i) gain insights into the underlying causes of oxidative stress in the male reproductive tract and (ii) develop optimized antioxidant preparations to treat pathologies arising from an imbalance in the redox status of these tissues. The journey will be long and difficult but ultimately more rewarding than the empirical approach that characterizes the current approach to treating the infertile male.

\section{References}

1. Free MJ, Schluntz GA, Jaffe RA. Respiratory gas tensions in tissues and fluids of the male rat reproductive tract. Biol Reprod 1976; 14:481-8.

2. Peltola V, Mantyla E, Huhtaniemi I, et al. Lipid peroxidation and antioxidant enzyme activities in the rat testis after cigarette smoke inhalation or administration of polychlorinated biphenyls or polychlorinated naphthalenes. J Androl 1994; 15:353-61.

3. Quinn PG, Payne AH. Oxygen-mediated damage of microsomal cytochrome P-450 enzymes in cultured leydig cells: Role in steroidogenic desensitization. J Biol Chem 1984; 259:4130-5.

4. Chen H, Liu J, Luo L, et al. Vitamin E, aging and Leydig cell steroidogenesis. Exp Gerontol 2005; 40:728-36.

5. Banfi B, Molnar G, Maturana A, et al. A Ca(2+)-activated NADPH oxidase in testis, spleen, and lymph nodes. J Biol Chem 2001; 276:37594-601.

6. Kumagai A, Kodama H, Kumagai J, et al. Xanthine oxidase inhibitors suppress testicular germ cell apoptosis induced by experimental cryptorchidism. Mol Hum Reprod. 2002; 8:118-23.

7. Zangar RC, Davydov DR, Verma S. Mechanisms that regulate production of reactive oxygen species by cytochrome P450. Toxicol Appl Pharmacol 2004; 199:316-331.

8. Kaur P, Kaur G, Bansal MP. Tertiary-butyl hydroperoxide induced oxidative stress and male reproductive activity in mice: Role of transcription factor NF-kappaB and testicular antioxidant enzymes. Reprod Toxicol 2006; 22:479-84.

9. Zini A, Schlegel PN. Catalase mRNA expression in the male rat reproductive tract. J Androl 1996; 17:473-80.

10. Peltola V, Huhtaniemi I, Ahotupa M. Antioxidant enzyme activity in the maturing rat testis. J Androl 1992; 13:450-5.

11. Mruk DD, Silvestrini B, Mo MY, et al. Antioxidant superoxide dismutase-A review: Its function, regulation in the testis, and role in male fertility. Contraception 2002; 65:305-11.

12. Ishii T, Matsuki S, Iuchi Y, et al. Accelerated impairment of spermatogenic cells in SOD1-knockout mice under heat stress. Free Radic Res 2005; 39:697-705.

13. Gu W, Hecht NB. Developmental expression of glutathione peroxidase, catalase, and manganese superoxide dismutase mRNAs during spermatogenesis in the mouse. J Androl 1996; $17: 256-62$. 
14. Vaisberg CN, Jelezarsky LV, Dishlianova B, et al. Activity, substrate detection and immunolocalization of glutathione peroxidase (GPx) in bovine reproductive organs and semen. Theriogenology 2005; 64:416-28.

15. Baek IJ, Seo DS, Yon JM, et al. Tissue expression and cellular localization of phospholipid hydroperoxide glutathione peroxidase (PHGPx) mRNA in male mice. J Mol Histol 2007; 38:237-44.

16. Kaur P, Bansal MP. Influence of selenium induced oxidative stress on spermatogenesis and lactate dehydrogenase-X in mice testis. Asian J Androl 2004; 6:227-32.

17. Avlan D, Erdougan K, Cimen B, et al. The protective effect of selenium on ipsilateral and contralateral testes in testicular reperfusion injury. Pediatr Surg Int 2005; 21:274-8.

18. Bray TM, Bettger WJ. The physiological role of zinc as an antioxidant. Free Radic Biol Med 1990; 8:281-91.

19. Nair N, Bedwal S, Prasad S, et al. Short-term zinc deficiency in diet induces increased oxidative stress in testes and epididymis of rats. Indian J Exp Biol 2005; 43:786-94.

20. Khan S, Khan MA, Bhatnagar D, et al. Zinc protection against lipid peroxidation from cadmium. Indian J Exp Biol 1991; 29:823-5.

21. Batra N, Nehru B, Bansal MP. The effect of zinc supplementation on the effects of lead on the rat testis. Reprod Toxicol 1998; 12:535-40.

22. Ozkan KKU, Boran C, Kilinc M, et al. The effect of zinc aspartate pretreatment on ischemia-reperfusion injury and early changes of blood and tissue antioxidant enzyme activities after unilateral testicular torsion-detorsion. J Pediatr Surg 2004; 39:91-5.

23. Amara S, Abdelmelek H, Garrel C, et al. Preventive Effect of zinc against cadmium-induced oxidative stress in the rat testis. J Reprod Dev 2008; 54:129-34.

24. Johnson FC. The antioxidant vitamins CRC. Crit Rev Food Sci Nutr 1979; 11:217-309.

25. Yoganathan T, Eskild W, Hansson V. Investigation of detoxification capacity of rat testicular germ cells and Sertoli cells. Free Radic Biol Med 1989; 7:355-9.

26. Paolicchi A, Pezzini A, Saviozzi M, et al. Localization of a GSH-dependent dehydroascorbate reductase in rat tissues and subcellular fractions. Arch Biochem Biophys 1996; 333:489-95.

27. Sonmez M, Turk G, Yuce A. The effect of ascorbic acid supplementation on sperm quality, lipid peroxidation and testosterone levels of male Wistar rats. Theriogenology 2005 63:2063-72.

28. Senthil kumar J, Banudevi S, Sharmila M, et al. Effects of Vitamin C and E on PCB (Aroclor 1254) induced oxidative stress, androgen binding protein and lactate in rat Sertoli cells. Reprod Toxicol 2004; 19:201-8.

29. Maneesh M, Jayalakshmi H, Dutta S, et al. Experimental therapeutic intervention with ascorbic acid in ethanol induced testicular injuries in rats. Indian J Exp Biol 2005; 43:172-6.

30. Rao M, Narayana K, Benjamin S, et al. L-ascorbic acid ameliorates postnatal endosulfan induced testicular damage in rats. Indian J Physiol Pharmacol 2005; 49:331-6.

31. Chang SI, Jin B, Youn P, et al. Arsenic-induced toxicity and the protective role of ascorbic acid in mouse testis. Toxicol Appl Pharmacol 2007; 218:196-203.

32. Sen Gupta R, Sen Gupta E, et al. Vitamin C and vitamin E protect the rat testes from cadmium-induced reactive oxygen species. Mol Cells 2004; 17:132-9.

33. Verma RJ, Nair A. Ameliorative effect of vitamin $\mathrm{E}$ on aflatoxin-induced lipid peroxidation in the testis of mice. Asian J Androl 2001; 3:217-21.

34. Aruldhas MM, Subramanian S, Sekar P, et al. Chronic chromium exposure-induced changes in testicular histoarchitecture are associated with oxidative stress: Study in a non-human primate (Macaca radiata Geoffroy). Hum Reprod 2005; 20:2801-13.

35. Marchlewicz M, Wiszniewska B, Gonet B, et al. Increased lipid peroxidation and ascorbic acid utilization in testis and epididymis of rats chronically exposed to lead. Biometals 2007; 20:13-9.

36. Lucesoli F, Fraga CG. Oxidative stress in testes of rats subjected to chronic iron intoxication and alpha-tocopherol supplementation. Toxicology 1999; 132:179-86.

37. Gavazza MB, Catala A. The effect of alpha-tocopherol on lipid peroxidation of microsomes and mitochondria from rat testis. Prostaglandins Leukot Essent Fatty Acids 2006; 74:247-54.

38. Ghosh D, Das UB, Misro M. Protective role of alpha-tocopherol-succinate (provitamin-E) in cyclophosphamide induced testicular gametogenic and steroidogenic disorders: A correlative approach to oxidative stress. Free Radic Res 2002; 36:1209-18.

39. Latchoumycandane C, Mathur PP. Effects of vitamin E on reactive oxygen species-mediated 2,3,7,8-tetrachlorodi-benzo-p-dioxin toxicity in rat testis. J Appl Toxicol 2002; 22:345-51.

40. Manna I, Jana K, Samanta PK. Intensive swimming exercise-induced oxidative stress and reproductive dysfunction in male wistar rats: Protective role of alpha-tocopherol succinate. Can J Appl Physiol 2004; 29:172-85.

41. Jedlinska-Krakowska M, Bomba G, et al. Impact of oxidative stress and supplementation with vitamins $\mathrm{E}$ and C on testes morphology in rats. J Reprod Dev 2006; 52:203-9.

42. Zhou DX, Qiu SD, Zhang J, et al. The protective effect of vitamin E against oxidative damage caused by formaldehyde in the testes of adult rats. Asian J Androl 2006; 8:584-8.

43. Mogulkoc R, Baltaci AK, Aydin L, et al. Pinealectomy increases oxidant damage in kidney and testis caused by hyperthyroidism in rats. Cell Biochem Funct 2006; 24:449-53.

44. Awad H, Halawa F, Mostafa T, et al. Melatonin hormone profile in infertile males. Int J Androl 2006; 29:409-13.

45. Semercioz A, Onur R, Ogras S, et al. Effects of melatonin on testicular tissue nitric oxide level and antioxidant enzyme activities in experimentally induced left varicocele. Neuro Endocrinol Lett 2003; 24:86-90.
46. Liu Z, Lin H, Ye S, et al. Remarkably high activities of testicular cytochrome c in destroying reactive oxygen species and in triggering apoptosis. Proc Natl Acad Sci USA 2006; 103:8965-70.

47. Ahotupa M, Huhtaniemi I. Impaired detoxification of reactive oxygen and consequent oxidative stress in experimentally cryptorchid rat testis. Biol Reprod 1992; 46:1114-8.

48. Ikeda M, Kodama H, Fukuda J, et al. Role of radical oxygen species in rat testicular germ cell apoptosis induced by heat stress. Biol Reprod 1999; 61:393-9.

49. Ishii T, Matsuki S, Iuchi $Y$, et al. Accelerated impairment of spermatogenic cells in SOD1-knockout mice under heat stress. Free Radic Res 2005; 39:697-705.

50. Smith GR, Kaune GH, Parodi ChD, et al. Extent of sperm DNA damage in spermatozoa from men examined for infertility: Relationship with oxidative stress. Rev Med Chil 2007; 135:279-86.

51. Chaki SP, Ghosh D, Misro MM. Simultaneous increase in germ cell apoptosis and oxidative stress under acute unilateral testicular ischaemia in rats. Int J Androl 2003; 26:319-28.

52. Taneli F, Vatansever S, Ulman C, et al. The effect of spermatic vessel ligation on testicular nitric oxide levels and germ cell-specific apoptosis in rat testis. Acta Histochem 2005; 106:459-66.

53. Lysiak JJ, Zheng S, Woodson R, et al. Caspase-9-dependent pathway to murine germ cell apoptosis: Mediation by oxidative stress, BAX, and caspase 2. Cell Tissue Res 2007; 328:411-49.

54. Guimaraes SB, Aragao AA, Santos JM, et al. Oxidative stress induced by torsion of the spermatic cord in young rats. Acta Cir Bras 2007; 22:30-3.

55. Anim JT, Kehinde EO, Prasad A, et al. Morphological responses of the rabbit testis to ischemic/reperfusion injury due to torsion. Urol Int 2005; 75:258-63.

56. Kehinde EO, Anim JT, Mojiminiyi OA, et al. Allopurinol provides long-term protection for experimentally induced testicular torsion in a rabbit model. BJU Int 2005; 96:686-7.

57. Unsal A, Eroglu M, Avci A, et al. Protective role of natural antioxidant supplementation on testicular tissue after testicular torsion and detorsion. Scand J Urol Nephrol 2006; 40:17-22.

58. Uguralp S, Usta U, Mizrak B. Resveratrol may reduce apoptosis of rat testicular germ cells after experimental testicular torsion. Eur J Pediatr Surg 2005; 15:333-6.

59. Dokmeci D, Inan M, Basaran UN, et al. Protective effect of L-carnitine on testicular ischaemia-reperfusion injury in rats. Cell Biochem Funct 2007; 25:611-8.

60. Atik E, Gorur S, Kiper AN. The effect of caffeic acid phenethyl ester (CAPE) on histopathological changes in testicular ischemia-reperfusion injury. Pharmacol Res 2006; 54:293-7.

61. Turner TT, Bang HJ, Lysiak JL. The molecular pathology of experimental testicular torsion suggests adjunct therapy to surgical repair. J Urol 2004; 172:2574-8.

62. Sarica K, Kupeli B, Budak M, et al. Influence of experimental spermatic cord torsion on the contralateral testis in rats: Evaluation of tissue free oxygen radical scavenger enzyme levels. Urol Int 1997; 58:208-12.

63. Saba M, Morales CR, De Lamirande E, et al. Morphological and biochemical changes following acute unilateral testicular torsion in prepubertal rats. J Urol 1997; 157:1149-54.

64. Filho DW, Torres MA, Bordin AL, et al. Spermatic cord torsion, reactive oxygen and nitrogen species and ischemia-reperfusion injury. Mol Aspects Med 2004; 25:199-210.

65. Hendin BN, Kolettis PN, Sharma RK, et al. Varicocele is associated with elevated spermatozoal reactive oxygen species production and diminished seminal plasma antioxidant capacity. J Urol 1999; 161:1831-4.

66. Agarwal A, Prabakaran S, Allamaneni SS. Relationship between oxidative stress, varicocele and infertility: A meta-analysis. Reprod Biomed Online 2006; 12:630-3.

67. Smith R, Kaune H, Parodi D, et al. Increased sperm DNA damage in patients with varicocele: Relationship with seminal oxidative stress. Hum Reprod 2006; 21:986-93.

68. Hurtado de Catalfo GE, Ranieri-Casilla A, Marra FA, et al. Oxidative stress biomarkers and hormonal profile in human patients undergoing varicocelectomy. Int J Androl 2007; 30:519-30.

69. Shiraishi K, Naito K. Generation of 4-hydroxy-2-nonenal modified proteins in testes predicts improvement in spermatogenesis after varicocelectomy. Fertil Steril 2006; 86:233-5.

70. Ishikawa T, Fujioka H, Ishimura T, et al. Increased testicular 8-hydroxy-2'-deoxyguanosine in patients with varicocele. BJU Int 2007; 100:863-6.

71. Ozdamar AS, Soylu AG, Culha M, et al. Testicular oxidative stress: Effects of experimental varicocele in adolescent rats. Urol Int 2004; 73:343-7.

72. Saleh RA, Agarwal A, Sharma RK, et al. Evaluation of nuclear DNA damage in spermatozoa from infertile men with varicocele. Fertil Steril 2003; 80:1431-6.

73. Pasqualotto FF, Sharma RK, Nelson DR, et al. Relationship between oxidative stress, semen characteristics, and clinical diagnosis in men undergoing infertility investigation. Fertil Steril 2000; 73:459-64.

74. Mitropoulos D, Deliconstantinos G, Zervas A, et al. Nitric oxide synthase and xanthine oxidase activities in the spermatic vein of patients with varicocele: A potential role for nitric oxide and peroxynitrite in sperm dysfunction. J Urol 1996; 156:1952-8.

75. Gomez E, Buckingham DW, Brindle J, et al. Development of an image analysis system to monitor the retention of residual cytoplasm by human spermatozoa: Correlation with biochemical markers of the cytoplasmic space, oxidative stress, and sperm function. J Androl 1996; 17:276-87.

76. Baker MA, Reeves G, Hetherington L, et al. Proteomic analysis of human spermatozoa. Proteomics Clin Appl 2007; 1:524-32.

77. Williams AC, Ford WC. Functional significance of the pentose phosphate pathway and glutathione reductase in the antioxidant defences of human sperm. Biol Reprod 2004 71:1309-16 
78. Zini A, Defreitas G, Freeman M, et al. Varicocele is associated with abnormal retention of cytoplasmic droplets by human spermatozoa. Fertil Steril 2000; 74:461-4.

79. Zini A, Buckspan M, Jamal M, et al. Effect of varicocelectomy on the abnormal retention of residual cytoplasm by human spermatozoa. Hum Reprod 1999; 14:1791-3.

80. Sahoo DK, Roy A, Chattopadhyay S, et al. Effect of T3 treatment on glutathione redox pool and its metabolizing enzymes in mitochondrial and post-mitochondrial fractions of adult rat testes. Indian J Exp Biol 2007; 45:338-46.

81. Zamoner A, Barreto KP, Filho DW, et al. Hyperthyroidism in the developing rat testis is associated with oxidative stress and hyperphosphorylated vimentin accumulation. Mol Cell Endocrinol 2007; 267:116-26.

82. Krassas GE, Pontikides N, Deligianni V, et al. A prospective controlled study of the impact of hyperthyroidism on reproductive function in males. J Clin Endocrinol Metab 2002; $87: 3667-71$.

83. Choudhury S, Chainy GB, Mishro MM. Experimentally induced hypo- and hyper-thyroidism influence on the antioxidant defence system in adult rat testis. Andrologia 2003; 35:131-40.

84. Mallick C, Mandal S, Barik B, et al. Protection of testicular dysfunctions by MTEC, a formulated herbal drug, in streptozotocin induced diabetic rat. Biol Pharm Bull 2007; 30:84-90.

85. Shrilatha B, Muralidhara. Early oxidative stress in testis and epididymal sperm in streptozotocin-induced diabetic mice: Its progression and genotoxic consequences. Reprod Toxicol 2007; 23:578-87.

86. Armagan A, Uz E, Yilmaz HR, et al. Effects of melatonin on lipid peroxidation and antioxidant enzymes in streptozotocin-induced diabetic rat testis. Asian J Androl 2006; 8:595-600.

87. Agbaje IM, Rogers DA, McVicar CM, et al. Insulin dependent diabetes mellitus: Implications for male reproductive function. Hum Reprod 2007; 22:1871-7.

88. Reddy MM, Mahipal SV, Subhashini J, et al. Bacterial lipopolysaccharide-induced oxidative stress in the impairment of steroidogenesis and spermatogenesis in rats. Reprod Toxicol 2006; 22:493-500.

89. Allen JA, Diemer T, Janus P, et al. Bacterial endotoxin lipopolysaccharide and reactive oxygen species inhibit Leydig cell steroidogenesis via perturbation of mitochondria. Endocrine 2004; 25:265-75.

90. Somani SM, Husain K. Exercise training alters kinetics of antioxidant enzymes in rat tissues. Biochem Mol Biol Int 1996; 38:587-95.

91. Husain K, Somani SM. Interaction of exercise training and chronic ethanol ingestion on testicular antioxidant system in rat. J Appl Toxicol 1998; 18:421-9.

92. Manna I, Jana K, Samanta PK. Effect of intensive exercise-induced testicular gametogenic and steroidogenic disorders in mature male Wistar strain rats: A correlative approach to oxidative stress. Acta Physiol Scand 2003; 178:33-40.

93. Zini A, Schlegel PN. Effect of hormonal manipulation on mRNA expression of antioxidant enzymes in the rat testis. J Urol 2003; 169:767-71.

94. Ghosh D, Das UB, Ghosh S, et al. Testicular gametogenic and steroidogenic activities in cyclophosphamide treated rat: A correlative study with testicular oxidative stress. Drug Chem Toxicol 2002; 25:281-92.

95. Peltola V, Huhtaniemi I, Metsa-Ketela T, et al. Induction of lipid peroxidation during steroidogenesis in the rat testis. Endocrinology 1996; 137:105-12.

96. Chainy GB, Samantaray S, Samanta L. Testosterone-induced changes in testicular antioxidant system. Andrologia 1997; 29:343-9.

97. Chaki SP, Misro MM, Gautam DK, et al. Estradiol treatment induces testicular oxidative stress and germ cell apoptosis in rats. Apoptosis 2006; 11:1427-37.

98. Gautam DK, Misro MM, Chaki SP, et al. hCG treatment raises $\mathrm{H}_{2} \mathrm{O}_{2}$ levels and induces germ cell apoptosis in rat testis. Apoptosis 2007; 12:1173-82.

99. Conte da Frota Jr ML, Gomes da Silva E, Behr GA, et al. All-trans retinoic acid induces free radical generation and modulate antioxidant enzyme activities in rat Sertoli cells. Mol Cell Biochem 2006; 285:173-9.

100. Klamt F, Dal-Pizzol F, Ribeiro NC, et al. Retinol-induced elevation of ornithine decarboxylase activity in cultured rat Sertoli cells is attenuated by free radical scavenger and by iron chelator. Mol Cell Biochem 2000; 208:71-6.

101. Dal-Pizzol F, Klamt F, Benfato MS, et al. Retinol supplementation induces oxidative stress and modulates antioxidant enzyme activities in rat sertoli cells. Free Radic Res 2001; 34:395-404

102. Murata M, Kawanishi S. Oxidative DNA damage by vitamin A and its derivative via superoxide generation. J Biol Chem 2000; 275:2003-8.

103. Biswas NM, Deb C. Testicular degeneration in rats during hypervitaminosis A. Endokrinologie 1965; 49:64-9.

104. Adamopoulos D, Venaki E, Koukkou E, et al. Association of carotene rich diet with hypogonadism in a male athlete. Asian J Androl 2006; 8:488-92.

105. Fraga CG, Motchnik PA, Wyrobek AJ, et al. Smoking and low antioxidant levels increase oxidative damage to sperm DNA. Mutat Res 1996; 351:199-203.

106. Fraga CG, Motchnik PA, Shigenaga MK, et al. Ascorbic acid protects against endogenous oxidative DNA damage in human sperm. Proc Natl Acad Sci USA 1991; 88:11003-6.

107. Ozyurt H, Pekmez H, Parlaktas BS, et al. Oxidative stress in testicular tissues of rats exposed to cigarette smoke and protective effects of caffeic acid phenethyl ester. Asian J Androl 2006; 8:189-93.

108. Nordmann R, Ribiere C, Rouach H. Ethanol-induced lipid peroxidation and oxidative stress in extrahepatic tissues. Alcohol Alcohol 1990; 25:231-7.
109. Schlorff EC, Husain K, Somani SM. Dose and time dependent effects of ethanol on antioxidant system in rat testes. Alcohol 1999; 18:203-14.

110. Amanvermez R, Demir S, Tuncel OK, et al. Alcohol-induced oxidative stress and reduction in oxidation by ascorbate/L-cys/ L-met in the testis, ovary, kidney, and lung of rat. Adv Ther 2005; 22:548-58.

111. Maneesh M, Jayalekshmi H, Dutta S, et al. Effect of exogenous lecithin on ethanol-induced testicular injuries in Wistar rats. Indian J Physiol Pharmacol 2005; 49:297-304.

112. Maneesh M, Dutta S, Chakrabarti A, et al. Alcohol abuse-duration dependent decrease in plasma testosterone and antioxidants in males. Indian J Physiol Pharmacol 2006; 50:291-6.

113. Acharya UR, Mishra M, Tripathy RR, et al. Testicular dysfunction and antioxidative defense system of Swiss mice after chromic acid exposure. Reprod Toxicol 2006; 22:87-91.

114. Lucesoli F, Caligiuri M, Roberti MF, et al. Dose-dependent increase of oxidative damage in the testes of rats subjected to acute iron overload. Arch Biochem Biophys 1999; 372:37-43.

115. Doreswamy K, Muralidhara. Genotoxic consequences associated with oxidative damage in testis of mice subjected to iron intoxication. Toxicology 2005; 206:169-78.

116. Santos FW, Oro T, Zeni G, et al. Cadmium induced testicular damage and its response to administration of succimer and diphenyl diselenide in mice. Toxicol Lett 2004; 152:255-63.

117. Koizumi T, Li ZG. Role of oxidative stress in single-dose, cadmium-induced testicular cancer. J Toxicol Environ Health 1992; 37:25-36.

118. Linares V, Belles M, Albina ML, et al. Assessment of the pro-oxidant activity of uranium in kidney and testis of rats. Toxicol Lett 2006; 167:152-61.

119. Chang SI, Jin B, Youn P, et al. Arsenic-induced toxicity and the protective role of ascorbic acid in mouse testis. Toxicol Appl Pharmacol 2007; 218:196-203.

120. Chandra AK, Ghosh R, Chatterjee A, et al. Effects of vanadate on male rat reproductive tract histology, oxidative stress markers and androgenic enzyme activities. J Inorg Biochem 2007; 101:944-56.

121. Kasahara E, Sato EF, Miyoshi M, et al. Role of oxidative stress in germ cell apoptosis induced by di(2-ethylhexyl)phthalate. Biochem J 2002; 365:849-56.

122. Lee E, Ahn MY, Kim HJ, et al. Effect of di(n-butyl) phthalate on testicular oxidative damage and antioxidant enzymes in hyperthyroid rats. Environ Toxicol 2007; 22:245-55.

123. Meng Z, Bai W. Oxidation damage of sulfur dioxide on testicles of mice. Environ Res 2004; 96:298-304

124. Ghosh D, Das Sarkar S, Maiti R, et al. Testicular toxicity in sodium fluoride treated rats: Association with oxidative stress. Reprod Toxicol 2002; 16:385-90.

125. Murugesan P, Balaganesh M, Balasubramanian K, et al. Effects of polychlorinated biphenyl (Aroclor 1254) on steroidogenesis and antioxidant system in cultured adult rat Leydig cells. J Endocrinol 2007; 192:325-38.

126. al-Bayati ZA, Wahba ZZ, Stohs SJ. 2,3,7,8-Tetrachlorodibenzo-p-dioxin (TCDD)-induced alterations in lipid peroxidation, enzymes, and divalent cations in rat testis. Xenobiotica 1988; 18:1281-9.

127. Latchoumycandane C, Chitra KC, Mathur PP. The effect of 2,3,7,8-tetrachlorodibenzo-p-dioxin on the antioxidant system in mitochondrial and microsomal fractions of rat testis. Toxicology 2002; 171:127-35.

128. Latchoumycandane C, Mathur PP. Effect of methoxychlor on the antioxidant system in mitochondrial and microsome-rich fractions of rat testis. Toxicology 2002; 176:67-75.

129. Latchoumycandane C, Mathur PP. Induction of oxidative stress in the rat testis after short-term exposure to the organochlorine pesticide methoxychlor. Arch Toxicol 2002; 76:692-8

130. Kabuto H, Hasuike S, Minagawa N, et al. Effects of bisphenol A on the metabolisms of active oxygen species in mouse tissues. Environ Res 2003; 93:31-5.

131. Chitra KC, Latchoumycandane C, Mathur PP. Induction of oxidative stress by bisphenol A in the epididymal sperm of rats. Toxicology 2003; 185:119-27.

132. Chitra KC, Latchoumycandane C, Mathur PP. Effect of nonylphenol on the antioxidant system in epididymal sperm of rats. Arch Toxicol 2002; 76:545-51.

133. Gong Y, Han XD. Nonylphenol-induced oxidative stress and cytotoxicity in testicular Sertoli cells. Toxicol 2006; 22:623-30.

134. Chitra KC, Mathur PP. Vitamin E prevents nonylphenol-induced oxidative stress in testis of rats. Indian J Exp Biol 2004; 42:220-3.

135. Prahalathan C, Selvakumar E, Varalakshmi P. Lipoic acid ameliorates adriamycin-induced testicular mitochondriopathy. Reprod Toxicol 2005; 20:111-6.

136. Atessahin A, Sahna E, Turk G, et al. Chemoprotective effect of melatonin against cisplatin-induced testicular toxicity in rats. J Pineal Res 2006; 41:21-7.

137. Atessahin A, Karahan I, Turk G, et al. Protective role of lycopene on cisplatin-induced changes in sperm characteristics, testicular damage and oxidative stress in rats. Reprod Toxicol 2006; 21:42-7.

138. Ghosh D, Das UB, Misro M. Protective role of alpha-tocopherol-succinate (provitamin-E) in cyclophosphamide induced testicular gametogenic and steroidogenic disorders: A correlative approach to oxidative stress. Free Radic Res 2002; 36:1209-18.

139. Ghosh D, Das UB, Ghosh S, et al. Testicular gametogenic and steroidogenic activities in cyclophosphamide treated rat: A correlative study with testicular oxidative stress. Drug Chem Toxicol 2002; 5:281-92.

140. Selvakumar E, Prahalathan C, Mythili Y, et al. Protective effect of DL-alpha-lipoic acid in cyclophosphamide induced oxidative injury in rat testis. Reprod Toxicol 2004; 19:163-7. 
141. Samanta L, Roy A, Chainy GB. Changes in rat testicular antioxidant defence profile as a function of age and its impairment by hexachlorocyclohexane during critical stages of maturation. Andrologia 1999; 31:83-90.

142. Samanta L, Sahoo A, Chainy GB. Age-related changes in rat testicular oxidative stress parameters by hexachlorocyclohexane. Arch Toxicol 1999; 73:96-107.

143. Homma-Takeda S, Hiraku Y, Ohkuma Y, et al. 2,4,6-trinitrotoluene-induced reproductive toxicity via oxidative DNA damage by its metabolite. Free Radic Res 2002; 36:555-66.

144. Verma RJ, Nair A. Ameliorative effect of vitamin $\mathrm{E}$ on aflatoxin-induced lipid peroxidation in the testis of mice. Asian J Androl 2001; 3:217-21.

145. Sujatha R, Chitra KC, Latchoumycandane C, et al. Effect of lindane on testicular antioxidant system and steroidogenic enzymes in adult rats. Asian J Androl 2001; 3:135-8.

146. Debnath D, Mandal TK. Study of quinalphos (an environmental oestrogenic insecticide) formulation (Ekalux 25 E.C.)-induced damage of the testicular tissues and antioxidant defence systems in Sprague-Dawley albino rats. J Appl Toxicol 2000; 20:197-204.

147. Rao M, Narayana K, Benjamin S, et al. L-ascorbic acid ameliorates postnatal endosulfan induced testicular damage in rats. Indian J Physiol Pharmacol 2005; 49:331-6.

148. Kaur P, Kalia S, Bansal MP. Effect of diethyl maleate induced oxidative stress on male reproductive activity in mice: Redox active enzymes and transcription factors expression. Mol Cell Biochem 2006; 291:55-61.

149. Singh M, Kalla NR, Sanyal SN. Effect of monensin on the enzymes of oxidative stress, thiamine pyrophosphatase and DNA integrity in rat testicular cells in vitro. Exp Toxicol Pathol 2006; 58:203-8.

150. Zhou DX, Qiu SD, Zhang J, et al. The protective effect of vitamin E against oxidative damage caused by formaldehyde in the testes of adult rats. Asian J Androl 2006; 8:584-8.

151. El-Missiry MA. Enhanced testicular antioxidant system by ascorbic acid in alloxan diabetic rats. Comp Biochem Physiol C Pharmacol Toxicol Endocrinol 1999; 124:233-7.

152. Ou SY, Jackson GM, Jiao X, et al. Protection against oxidative stress in diabetic rats by wheat bran feruloyl oligosaccharides. J Agric Food Chem 2007; 55:3191-5.

153. Yousef MI, El-Demerdash FM. Acrylamide-induced oxidative stress and biochemical perturbations in rats. Toxicology 2006; 219:133-41.

154. Jedlinska-Krakowska M, Bomba G, Jakubowski K, et al. Impact of oxidative stress and supplementation with vitamins $\mathrm{E}$ and $\mathrm{C}$ on testes morphology in rats. J Reprod Dev 2006; 52:203-9.

155. Amara S, Abdelmelek H, Garrel C, et al. Effects of subchronic exposure to static magnetic field on testicular function in rats. Arch Med Res 2006; 37:947-52.

156. Ikeda M, Kodama H, Fukuda J, et al. Role of radical oxygen species in rat testicular germ cell apoptosis induced by heat stress. Biol Reprod 1999; 61:393-9.

157. Manda K, Ueno M, Moritake T, et al. Alpha-lipoic acid attenuates x-irradiation-induced oxidative stress in mice. Cell Biol Toxicol 2007; 23:129-37.

158. Cay A, Alver A, Kucuk M, et al. The effects of N-acetylcysteine on antioxidant enzyme activities in experimental testicular torsion. J Surg Res 2006; 131:199-203.

159. Liu ZM, Zheng XM, Yang ZW, et al. Protective effect of pentoxifylline on spermatogenesis following testicular torsion/detorsion in rats. Zhonghua Nan Ke Xue 2006; 12:323-5.

160. Koc A, Narci A, Duru M, et al. The protective role of erdosteine on testicular tissue after testicular torsion and detorsion. Mol Cell Biochem 2005; 280:193-9.

161. Etensel B, Ozkisacik S, Ozkara E, et al. The protective effect of dexpanthenol on testicular atrophy at 60th day following experimental testicular torsion. Pediatr Surg Int 2007; 23:271-5.

162. Yagmurdur H, Ayyildiz A, Karaguzel E, et al. The preventive effects of thiopental and propofol on testicular ischemia-reperfusion injury. Acta Anaesthesiol Scand 2006; 50:1238-43.

163. Ozyurt B, Parlaktas BS, Ozyurt H, et al. A preliminary study of the levels of testis oxidative stress parameters after MK-801-induced experimental psychosis model: Protective effects of CAPE. Toxicology 2007; 230:83-9.

164. Turk G, Atessahin A, Sonmez M, et al. Lycopene protects against cyclosporine A-induced testicular toxicity in rats. Theriogenology 2007; 67:778-85.

165. Luo Q, Li Z, Huang X, et al. Lycium barbarum polysaccharides: Protective effects against heat-induced damage of rat testes and $\mathrm{H} 2 \mathrm{O} 2$-induced DNA damage in mouse testicular cells and beneficial effect on sexual behavior and reproductive function of hemicastrated rats. Life Sci 2006; 79:613-21.

166. El-Missiry MA, Shalaby F. Role of beta-carotene in ameliorating the cadmium-induced oxidative stress in rat brain and testis. J Biochem Mol Toxicol 2000; 14:238-43.

167. Oner-Iyidogan Y, Gurdol F, Oner P. The effects of acute melatonin and ethanol treatment on antioxidant enzyme activities in rat testes. Pharmacol Res 2001; 44:89-93.

168. Othman AI, El-Missiry MA, Amer MA. The protective action of melatonin on indomethacin-induced gastric and testicular oxidative stress in rats. Redox Rep 2001; 6:173-7.

169. Hussein MR, Abu-Dief EE, Abou El-Ghait AT, et al. Melatonin and roentgen irradiation of the testis. Fertil Steril 2006; 86:750-2.

170. Gavazza M, Catala A. Melatonin preserves arachidonic and docosapentaenoic acids during ascorbate-Fe2+ peroxidation of rat testis microsomes and mitochondria. Int J Biochem Cell Biol 2003; 35:359-66.

171. Gavazza MB, Catala A. Protective effect of N-acetyl-serotonin on the non-enzymatic lipid peroxidation in rat testicular microsomes and mitochondria. J Pineal Res 2004; 37:153-60.

172. Juan ME, Gonzalez-Pons E, Munuera T, et al. Trans-resveratrol, a natural antioxidant from grapes, increases sperm output in healthy rats. J Nutr 2005; 135:757-60.
173. Orozco TJ, Wang JF, Keen CL. Chronic consumption of a flavanol- and procyanindin-rich diet is associated with reduced levels of 8-hydroxy-2'-deoxyguanosine in rat testes. J Nutr Biochem 2003; 14:104-10.

174. Suleiman SA, Ali ME, Zaki ZM, et al. Lipid peroxidation and human sperm motility: Protective role of vitamin E. J Androl 1996; 17:530-7.

175. Keskes-Ammar L, Feki-Chakroun N, Rebai T, et al. Sperm oxidative stress and the effect of an oral vitamin $\mathrm{E}$ and selenium supplement on semen quality in infertile men. Arch Androl 2003; 49:83-94.

176. Aitken RJ, De Iuliis GN. Origins and consequences of DNA damage in male germ cells. Reprod Biomed Online 2007; 14:727-33.

177. Aitken RJ, Baker MA. Oxidative stress, sperm survival and fertility control. Mol Cell Endocrinol 2006; 250:66-9.

178. Aitken RJ. Founders' Lecture: Human spermatozoa: Fruits of creation, seeds of doubt. Reprod Fertil Dev 2004; 16:655-64.

179. Aitken RJ. The Amoroso Lecture: The human spermatozoon-A cell in crisis? J Reprod Fertil 1999; 115:1-7.

180. Sikka SC. Relative impact of oxidative stress on male reproductive function. Curr Med Chem 2001; 8:851-62.

181. Agarwal A, Gupta S, Sikka S. The role of free radicals and antioxidants in reproduction. Curr Opin Obstet Gynecol 2006; 18:325-32.

182. Kumar TR, Muralidhara. Male-mediated dominant lethal mutations in mice following prooxidant treatment. Mutat Res 1999; 444:145-9.

183. Hales DB, Allen JA, Shankara T, et al. Mitochondrial function in Leydig cell steroidogenesis. Ann N Y Acad Sci 2005; 1061:120-34.

184. Naughton CK, Nangia AK, Agarwal A. Pathophysiology of varicoceles in male infertility. Hum Reprod Update 2001; 7:473-81.

185. Agarwal A, Gupta S, Sikka S. The role of free radicals and antioxidants in reproduction. Curr Opin Obstet Gynecol 2006; 18:325-32.

186. Uz E, Sogut S, Sahin S, et al. The protective role of caffeic acid phenethyl ester (CAPE) on testicular tissue after testicular torsion and detorsion. World J Urol 2002; 20:264-70.

187. Salmasi AH, Beheshtian A, Payabvash S, et al. Effect of morphine on ischemia-reperfusion injury: Experimental study in testicular torsion rat model. Urology 2005; 66:1338-42. 


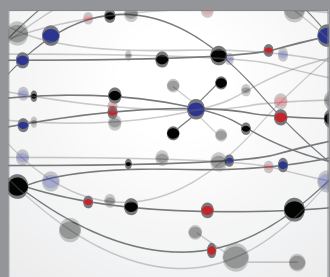

The Scientific World Journal
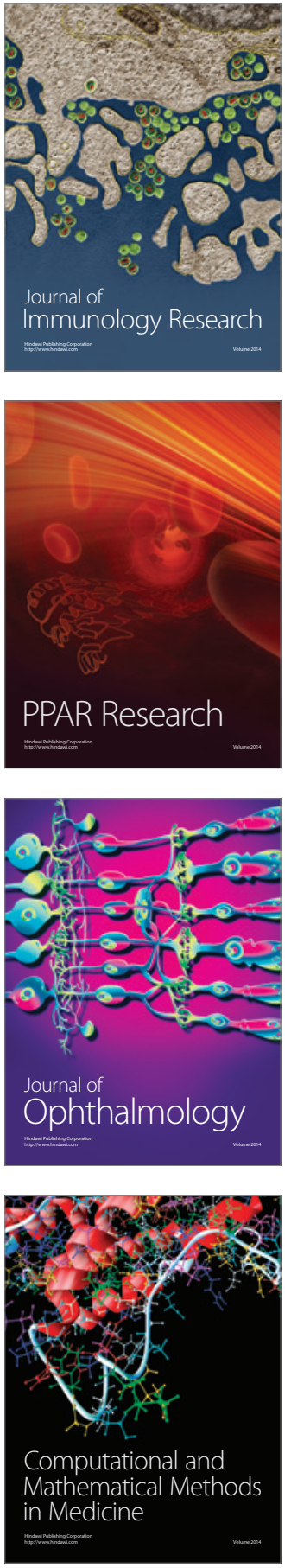

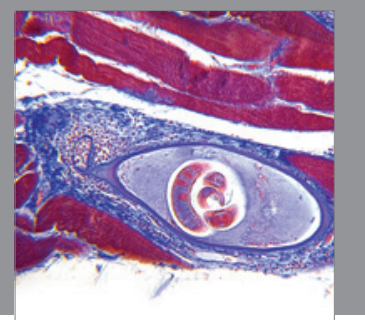

Gastroenterology

Research and Practice
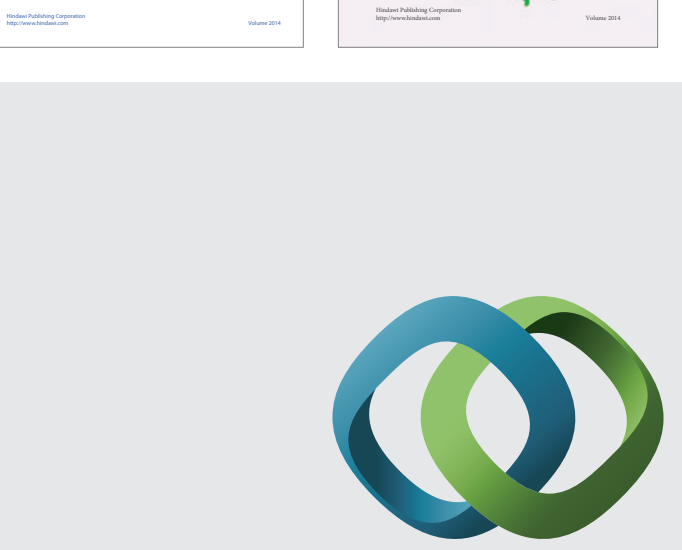

\section{Hindawi}

Submit your manuscripts at

http://www.hindawi.com
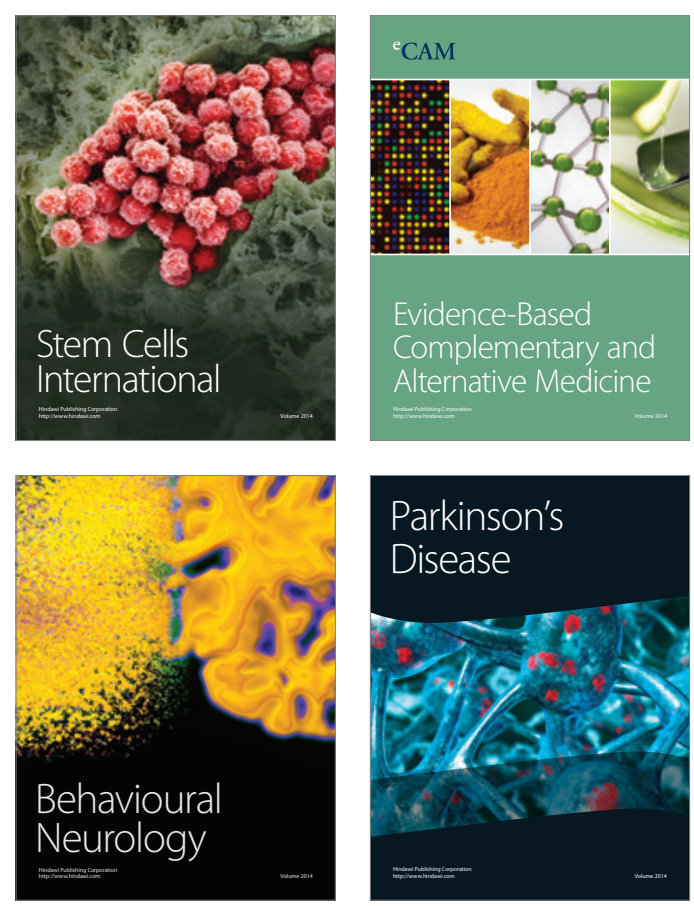

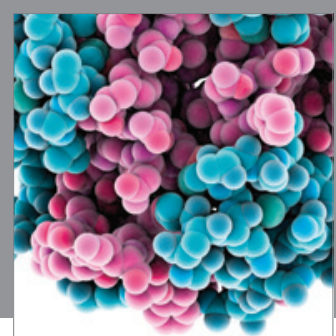

Journal of
Diabetes Research

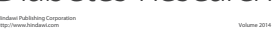

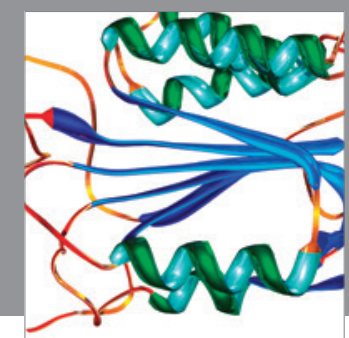

Disease Markers
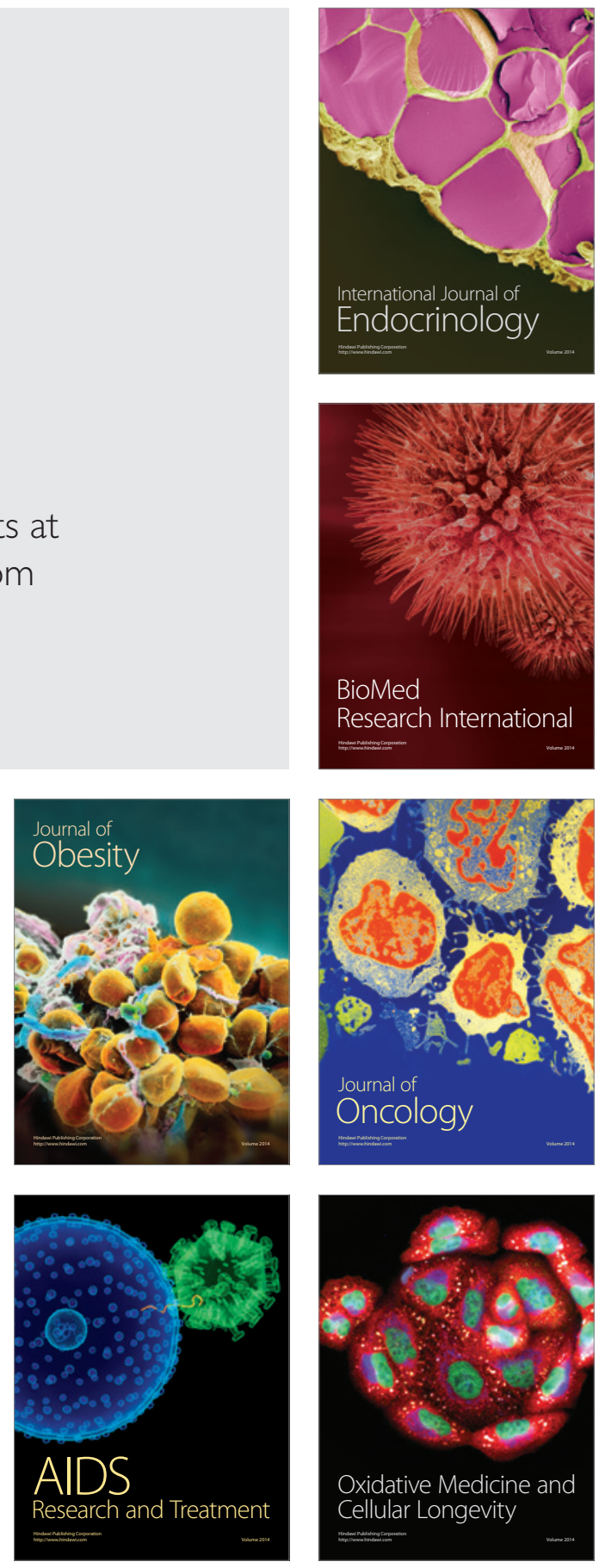